16

\title{
Синтез и оптические свойства пленок оксида титана, модифицированных кобальтом
}

\author{
(C) В.А. Логачева ${ }^{1}$, А.Н. Лукин ${ }^{1}$, Н.Н. Афонин ${ }^{2}$, О.В. Сербин ${ }^{1}$ \\ ${ }^{1}$ Воронежский государственный университет, \\ 394018 Воронеж, Россия \\ ${ }^{2}$ Воронежский государственный педагогический университет, \\ 394043 Воронеж, Россия \\ e-mail: kcmf@main.vsu.ru
}

Поступила в редакцию 24.01.2019 г.

В окончательной редакции 24.01.2019 г.

Принята к публикации 05.02.2019 г.

Методами рентгено-фазового анализа, растровой электронной микроскопии, атомно-силовой и магнитносиловой микроскопии, ИК спектроскопии исследованы свойства поликристаллических пленок $\mathrm{TiO}_{2}$, модифицированных кобальтом путем магнетронного распыления и последующей импульсной фотонной обработки на воздухе. Установлено, что в процессе модификации происходит формирование нанокристаллической (с размерами зерен $\sim 50 \mathrm{~nm}$ ) пленки, состоящей из оксидов кобальта и титана, поверхность которых проявляет магнитные свойства. В ИК спектрах отражения, полученных при разных углах падения луча, в области 500-600 $\mathrm{cm}^{-1}$ наблюдали две полосы поперечных (ТО) и соответствующие им две полосы продольных колебательных мод (LO), которые идентифицируют образование $\mathrm{Co}_{3} \mathrm{O}_{4}$ в структуре шпинели. Исследование оптического поглощения указывает на преимущественное существование в пленках фаз с прямозонными оптическими переходами с энергией 1.43 и $1.83 \mathrm{eV}$ для $\mathrm{Co}_{3} \mathrm{O}_{4}$ и $2.65 \mathrm{eV}$ для кубической фазы $\mathrm{CoO}$.

DOI: $10.21883 /$ OS.2019.06.47769.32-19

\section{Введение}

Диоксид титана $\mathrm{TiO}_{2}$ обладает высокой стойкостью к процессам фотокоррозии, широко распространен в природе и не является токсичным. Он имеет широкий круг применения и используется в солнечных и топливных элементах, химических источниках тока, защитных и оптических покрытиях, газовых сенсорах, электрохромных устройствах, варисторах, самоочищающихся поверхностях, фотокатализаторах для деструкции токсичных органических соединений, в процессах фотоэлектрохимического разложения воды для получения водорода [1]. Ширина запрещенной зоны диоксида титана составляет $3.2 \mathrm{eV}$ (для анатаза и брукита) и $3.0 \mathrm{eV}$ (для рутила) [2]. Поэтому он проявляет значительную фотокаталитическую активность только при воздействии ультрафиолетового излучения с длиной волны меньше $400 \mathrm{~nm}$, а следовательно проведение фотокаталитических реакций с применением $\mathrm{TiO}_{2}$ требует использования специальных ультрафиолетовых источников [3]. Расширение спектра поглощения в видимую область позволило бы применять солнечное излучение. Одним из подходов, используемых для изменения оптических свойств $\mathrm{TiO}_{2}$, является легирование оксида титана ионами переходных металлов.

Модификация оксида титана кобальтом представляет особый интерес, поскольку оксиды кобальта, образующиеся в $\mathrm{TiO}_{2}$, обладают привлекательными оптически- ми, магнитными, электронными и химическими свойствами. Они широко применяются в катализе [4], как анодные материалы в литий-ионных аккумуляторах $[5,6]$. В пленочном исполнении они используются как электрохимические суперконденсаторы [7], применяются в спинтронике [8] и газовых сенсорах [9]. Стабильными являются два антиферромагнитных оксида кобальта: $\mathrm{CoO}$ кубической структуры с шириной запрещенной зоны $2.2-2.8 \mathrm{eV}$ и температурой Нееля $298 \mathrm{~K}[10$ 12] и $\mathrm{Co}_{3} \mathrm{O}_{4}$ шпинельной структуры - полупроводник $p$-типа с шириной запрещенной зоны $1.4-1.8 \mathrm{eV}$ и температурой Нееля $40 \mathrm{~K}$ [13] Известно, что катионы $\mathrm{Co}^{3+}$ распределены в шпинели в октаэдрических позициях. Все $d$-электроны $\mathrm{Co}^{3+}$ спарены и не проявляют магнитных моментов. Ионы $\mathrm{Co}^{2+}-$ тетраэдрически координируются с ионами кислорода, имеют три неспаренных $d$-электрона, приводящих к магнитным моментам $3 \mu \mathrm{B}[14,15] . \mathrm{Co}_{3} \mathrm{O}_{4}$ устойчив до $800^{\circ} \mathrm{C}$ и разлагается до $\mathrm{CoO}$ при температуре выше $900^{\circ} \mathrm{C}$. Следовательно, ферромагнетизм, активируемый в антиферромагнитном полупроводнике $\mathrm{Co}_{3} \mathrm{O}_{4}$, позволяет использовать его в спинтронике для хранения и обработки информации $[16,17]$.

Целью работы было исследование оптических свойств пленок оксида титана, модифицированных кобальтом в процессе магнетронного распыления металла и последующей импульсной фотонной обработки. 


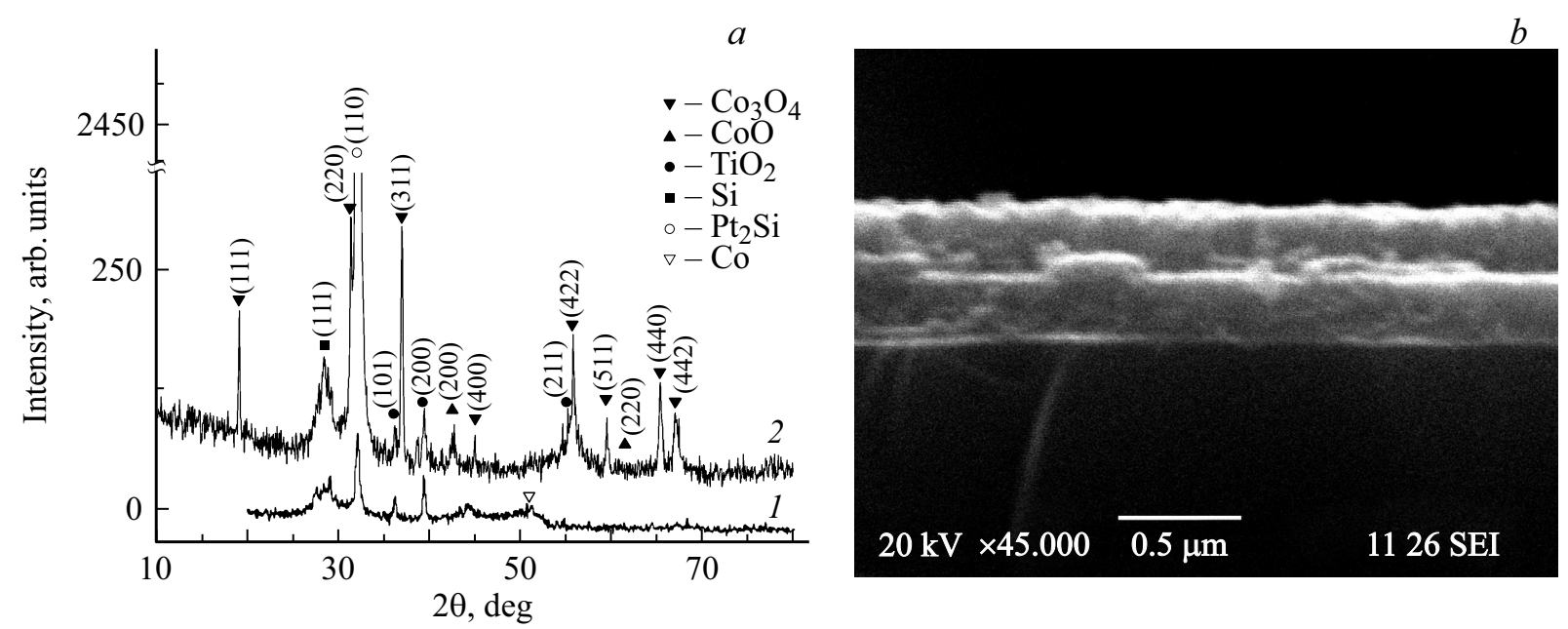

Рис. 1. Дифрактограмма $(a)$ и скол $(b)$ пленочной системы $\mathrm{Co}-\mathrm{TiO}_{2} / \mathrm{Pt} / \mathrm{Si}$ после ИФО при $E=120 \mathrm{~J} / \mathrm{cm}^{2}$.

\section{Методика эксперимента}

В настоящей работе поликристаллические пленки оксида титана толщиной $200 \mathrm{~nm}$ в структуре рутила получали путем магнетронного распыления металлического титана на подложки монокристаллического кремния с подслоем платины (для предотвращения диффузии кремния в оксидную пленку) с последующим термооксидированием титана в потоке кислорода при $T=973 \mathrm{~K}$ в течение $30 \mathrm{~min}$.

Модификацию оксида титана кобальтом осуществляли в два этапа. На первом этапе магнетронным распылением в плазме аргона осаждали кобальт на оксид титана при давлении в камере $13.3 \cdot 10^{-2} \mathrm{~Pa}$, токе разряда $0.5 \mathrm{~A}$, напряжении разряда $420 \mathrm{~V}$, скорости распыления кобальта $1.13 \mathrm{~nm} / \mathrm{s}$. Толщина пленки кобальта задавалась временем распыления и составляла $100 \mathrm{~nm}$. В результате была сформирована двухслойная пленочная система $\mathrm{Co}-\mathrm{TiO}_{2} / \mathrm{Pt} / \mathrm{Si}$. На втором этапе образцы подвергали импульсной фотонной обработке (ИФО) на модернизированной установке УОЛ.П-1. Нагрев осуществляли излучением трех газоразрядных ксеноновых ламп ИНП 16/250 с некогерентным излучением в диапазоне $0.2-1.2 \mu \mathrm{m}$. Процедуру ИФО проводили на воздухе с заданными параметрами энергии излучения, поступающей на поверхность образца: $E=90,110,120 \mathrm{~J} / \mathrm{cm}^{2}$.

Фазовый состав композитных пленок исследовали с применением дифрактометра ARL X'TRA. Толщину пленок определяли методом растровой электронной микроскопии (РЭМ) на сколах образцов в растровом электронном микроскопе JSM-6510 LV с разрешающей способностью в высоком вакууме $4 \mathrm{~nm}$.

Морфологию поверхности изучали методом атомносиловой микроскопии (ACM) на сканирующем зондовом микроскопе Solver P47PRO в полуконтактном режиме с использованием кантилевера HA_NC. Магнитная си- ловая микроскопия (МСМ) образцов была проведена с использованием кантилевера MFM_LM.

Измерение спектров отражения пленочной системы проводилось на инфракрасном фурье-спектрометре Vertex-70 фирмы Брукер (Германия) в диапазоне $4000-400 \mathrm{~cm}^{-1}$ при комнатной температуре с применением приставки зеркального отражения с регулируемым углом падения при 13, 45 и 70. Поскольку исследуемый образец представляет собой гетероструктуру, содержащую несколько фаз, то в зависимости от глубины проникновения ИК излучения можно было наблюдать как спектры отражения-поглощения (RAS), так и зеркального отражения от поверхности. Оптические свойства тонкопленочных структур в видимой и ультрафиолетовой областях спектра (190-900 nm) исследовали с использованием спектрофотометра Lambda-650 фирмы Percin Elmer (CША) с приставкой зеркального отражения URA при угле падения-отражения $8^{\circ}$.

\section{Результаты и их обсуждение}

После магнетронного распыления кобальта методом РФА в пленочной системе $\mathrm{Co}-\mathrm{TiO}_{2} / \mathrm{Pt} / \mathrm{Si}$ были обнаружены следующие фазы: $\mathrm{Co}, \mathrm{TiO}_{2}$ в структуре рутила, $\mathrm{Pt}$ и Si. Взаимодействия кобальта с оксидом титана в процессе магнетронного распыления не происходит (рис. 1, $a$, кривая 1).

После ИФО на воздухе в течение $1.3 \mathrm{~s}$ при энергии $E=120 \mathrm{~J} / \mathrm{cm}^{2}$ происходит образование $\mathrm{Co}_{3} \mathrm{O}_{4}$ гранецентрированной кубической структуры шпинели (пространственная группа $F d 3 m$ ) с параметром решетки $a=8.065 \AA ̊$. На дифрактограмме доминируют его рефлексы, зарегистрированные при следующих значениях $2 \theta: 19.02,31.32,36.9,38.65,55.68,59.42,65.37^{\circ}$ [JCPDS Card no. 01-074-1656]. Дифракционные рефлексы при значениях $2 \theta=42.6,61.8^{\circ}$ отражают образование $\mathrm{CoO}$ кубической структуры с параметром решетки 

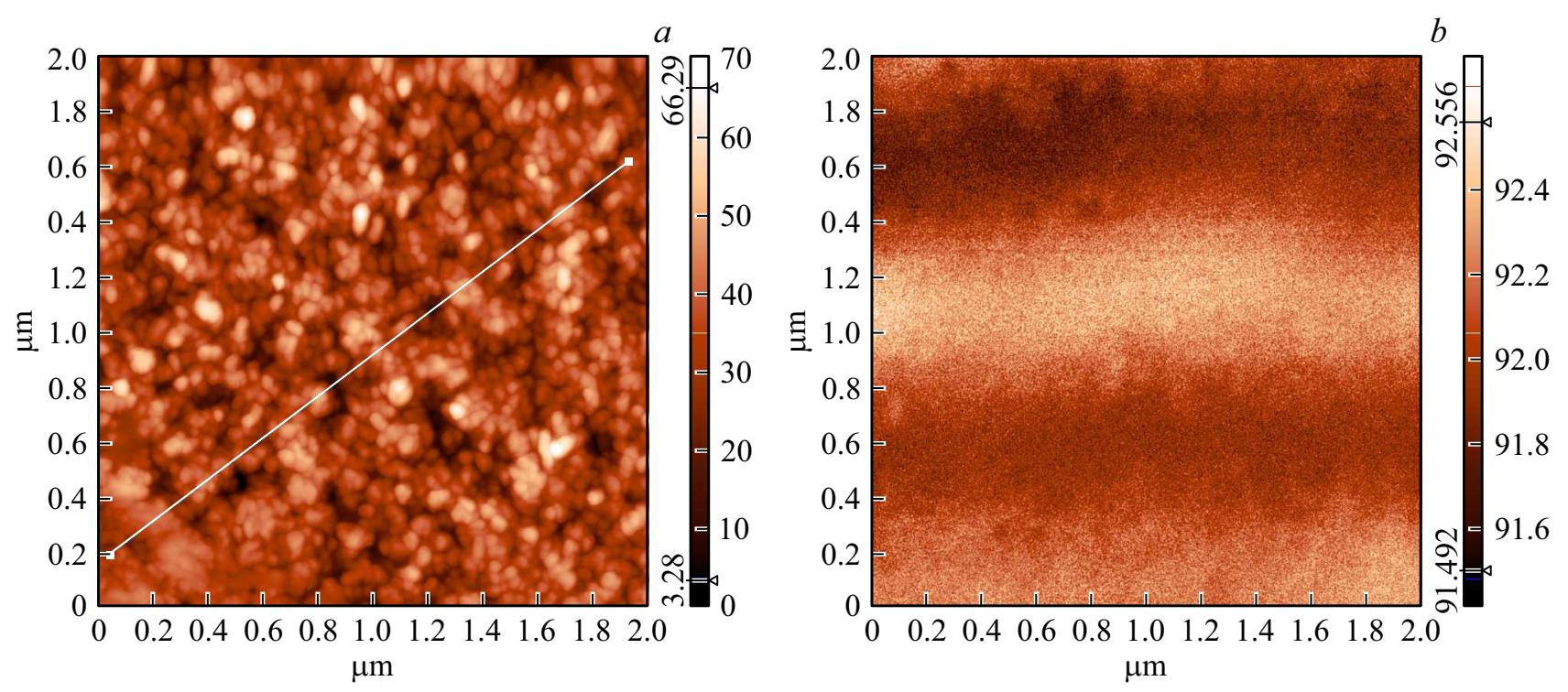

Рис. 2. Изображение поверхности $2 \times 2 \mu \mathrm{m}$ пленочного образца системы $\mathrm{Co}-\mathrm{TiO}_{2} / \mathrm{Pt} / \mathrm{Si}$ после ИФО при $E=120 \mathrm{~J} / \mathrm{cm}^{2}: a-$ топография поверхности (метод АСM), $b$ - распределение градиента магнитных сил (метод МСМ).

$a=4.240 \AA$ (пространственная группа $F m 3 m$ ) [JCPDS Card no. 01-075-0418]. На дифрактограмме также присутствуют незначительной интенсивности рефлексы оксида титана $\mathrm{TiO}_{2}$ тетрагональной структуры рутила (пространственная группа $P 42 / \mathrm{mnm})$ с параметрами решетки $a=b=4.5890 \AA, c=2.9540 \AA$ [JCPDS Card no. 01-0731765]. Кроме того, в процессе ИФО происходит образование силицида платины тетрагональной структуры $\mathrm{Pt}_{2} \mathrm{Si}$ (пространственная группа $I 4 / \mathrm{mmm}$ ), параметры решетки $a=b=3.9480 \AA, c=5.9630 \AA$ ([JCPDS Card no. 03-065-7973] (рис. 1, $a$, кривая 2). Обнаруженное методом РФА фазообразование в процессе ИФО объясняется образованием большой концентрации неравновесных вакансий в зоне локализации светового излучения, приводящего к ускорению контролируемых диффузией твердофазных процессов [18].

На микрофотографии скола пленочной структуры видны 2 слоя: нижний $\mathrm{TiO}_{2}$ толщиной $\sim 300 \mathrm{~nm}$ и верхний слой оксида кобальта толщиной $\sim 350 \mathrm{~nm}$ (рис. $1, b$ ). Следует отметить, что граница раздела пленка оксида кремний резкая, без следов диффузии кремния.

АCM- и МСМ-изображения поверхности пленочной системы $\mathrm{Co}-\mathrm{TiO}_{2} / \mathrm{Pt} / \mathrm{Si}$ после ИФО при $E=120 \mathrm{~J} / \mathrm{cm}^{2}$ представлены на рис. 2. Поверхность гладкая с зернами овальной формы размером $30-50 \mathrm{~nm}$. Мелкие зерна, соединяясь между собой, образуют агломераты (рис. $2, a$ ). Результаты исследования магнитного отклика показали, что на поверхности формируются магнитные домены лентообразной формы, МСМ-изображение которых явно не коррелирует с топографическим АСМизображением. Магнитные домены представляют собой равномерно распределенные параллельные полосы с периодом $\sim 500 \mathrm{~nm}$ (рис. $2, b)$.
Известно, что ионы $\mathrm{Co}^{3+}$, находясь в низкоспиновом состоянии в октаэдрический позициях в объеме материала, не имеют магнитного момента, в то время как ионы $\mathrm{Co}^{2+}$ в тетраэдрический позициях проявляют отличный от нуля магнитный момент. На поверхности объемная симметрия кристалла нарушается, каждый ион кобальта $\mathrm{Co}^{3+}$ связан с другим посредством одного кислородного атома в отличие от объема, где связь осуществляется посредством двух атомов кислорода. В [19] методом молекулярной динамики установлено, что ионы $\mathrm{Co}^{3+}$ поверхностного слоя имеют отличные от нуля магнитные моменты. Кроме того, ферромагнетизм может быть следствием взаимодействия антиферромагнитного оксида $\mathrm{Co}_{3} \mathrm{O}_{4}$ и парамагнитного $\mathrm{TiO}_{2}$. В [20] показано, что низкотемпературный отжиг $\left(<500^{\circ} \mathrm{C}\right)$ приводит к восстановлению иона $\mathrm{Co}^{+3}$ в октаэдрических позициях до $\mathrm{Co}^{+2}$ в результате взаимодействия на межфазных границах $\mathrm{Co}_{3} \mathrm{O}_{4}$ с анатазом. В нашем случае диффузия катионов металлов $\mathrm{Ti}^{+4}$ и $\mathrm{Co}^{+3}$, активированная ИФО, может привести к модификации электронной конфигурации оксидов и проявлению магнитных свойств. Таким образом, магнитный сигнал на поверхности композитной пленки мог возникнуть на межфазных границах двух оксидов: $\mathrm{Co}_{3} \mathrm{O}_{4}$ и $\mathrm{TiO}_{2}$, взаимодействие которых активируется ИФО и приводит к образованию сложных оксидов. Но на первых этапах реакции они не обнаруживаются методом РФА, поскольку представляют очень незначительную часть всего материала пленки.

Для уточнения природы наблюдаемого поверхностного магнетизма необходимо сопоставить магнитные свойства с другими свойствами, чувствительными к модификации электронной конфигурации оксидов. Поэтому были исследованы оптические свойства синтезированной 


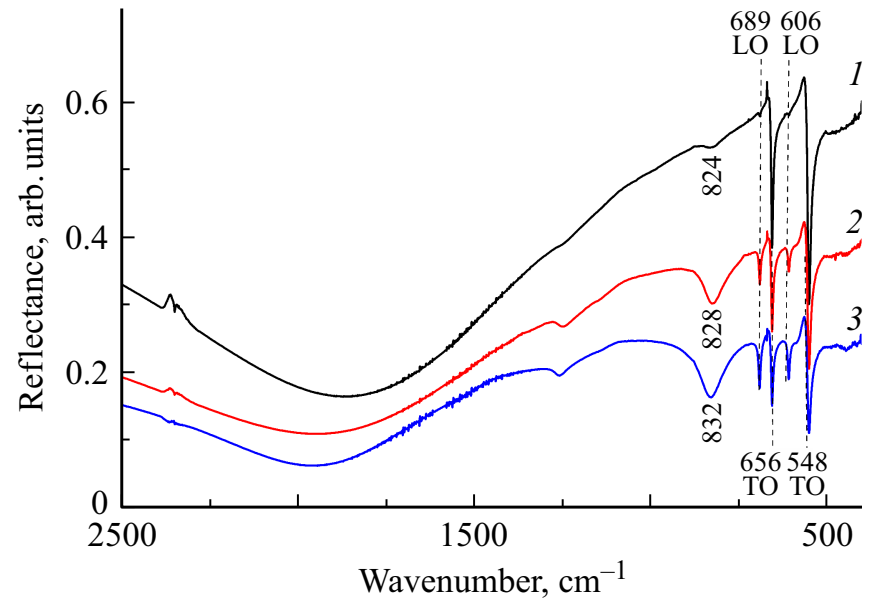

Рис. 3. Инфракрасные спектры пленочного образца системы $\mathrm{Co}-\mathrm{TiO}_{2} / \mathrm{Pt} / \mathrm{Si}$ после ИФО при $E=120 \mathrm{~J} / \mathrm{cm}^{2}$, полученные при углах падения $13(1), 45(2), 70^{\circ}(3)$.

композитной пленки методом ИК спектроскопии. Оптические свойства чувствительны к нарушениям симметрии атомов на поверхности, возникновению новых электронных уровней поверхностных состояний, приводящих к сдвигам характеристических полос в ИК спектре. Кроме того, анализ спектров отражения-поглощения (RAS) является простым неразрушающим экспериментальным методом для исследования оптических свойств как объема образцов, так и их поверхности. В зависимости от угла падения анализирующего луча можно наблюдать как LO- (продольные), так и TO- (поперечные) полосы поглощения оптических фононов.

На рис. 3 представлены ИК спектры RAS пленочной структуры Co- $\mathrm{TiO}_{2} / \mathrm{Pt} / \mathrm{Si}$ после ИФО при $E=120 \mathrm{~J} / \mathrm{cm}^{2}$. При угле падения луча $13^{\circ}$, близком к нормальному, в области 600-500 $\mathrm{cm}^{-1}$ в ИК спектре RAS пленки (рис. 3, кривая 1) наблюдали только две полосы поглощения 653 и $548 \mathrm{~cm}^{-1}$, которые относятся к поперечным (ТО) колебаниям связи Со-О для $\mathrm{Co}_{3} \mathrm{O}_{4}$ [21]. Аналогичные полосы присутствуют в спектрах оксидов кобальта, синтезированных другими методами, в частности микроволновыми [22]. Полоса $653 \mathrm{~cm}^{-1}$ относится к валентным колебаниям связи Со-O, характерным для переходов $d-d$ ионов $\mathrm{Co}^{2+}$ в тетраэдрических позициях [23], а $548 \mathrm{~cm}^{-1}$ - для $\mathrm{Co}^{3+}$ в октаэдрических позициях шпинели [24,25].

В спектрах отражениях, снятых при скользящих углах падения луча 45 и 70 , можно наблюдать четыре полосы поглощения (рис. 3, кривые 2,3). К уже обнаруженным двум ТО-колебательным модам в спектре появляются и усиливаются с увеличением угла падения возбуждающего излучения соответствующие им LO-полосы поглощения при 689 и $606 \mathrm{~cm}^{-1}$, которые происходят из продольных колебательных мод связи металла с кислородом и подтверждают образование $\mathrm{Co}_{3} \mathrm{O}_{4}$ в структуре шпинели [26].
Таким образом, скользящий угол падения луча позволяет наблюдать обе колебательные моды LO и TO, характерные для $\mathrm{Co}_{3} \mathrm{O}_{4}$. Отсутствие продольных LOколебательных мод при нормальном угле падения объясняется тем, что они возбуждаются только $s$-поляризованным лучом света. ТО-колебательные моды остаются более сильными по интенсивности в спектре отражения $\mathrm{Co}_{3} \mathrm{O}_{4}$, чем LO, даже под углом падения $70^{\circ}$, потому что они возбуждаются как $s$-, так и $p$-поляризованными лучами света. Еще одно важное замечание состоит в том, что положения всех четырех фононов остаются неизменными даже при изменении угла падения анализирующего луча.

Помимо полос поглощения, характеризующих оксиды кобальта, в спектре RAS присутствует полоса поглощения в области $800 \mathrm{~cm}^{-1}$, соответствующая валентным колебаниям связей $v(\mathrm{Ti}-\mathrm{O})$, обусловленным искажениями симметрии координационного окружения $\mathrm{Ti}^{+4}[27,28]$. Появление этой полосы связано с включением Со в решетку $\mathrm{TiO}_{2}$. В результате замены ионами кобальта $\mathrm{Co}^{2+}$ ионов $\mathrm{Ti}^{+4}$ для сохранения электронейтральности создаются кислородные вакансии. Отсутствие атомов кислорода в решетке, вызванное легированием $\mathrm{Co}^{2+}$, уменьшает число связей $\mathrm{Ti}-\mathrm{O}$, что подразумевает понижении симметрии.

Изменяя угол падения $\theta$ анализирующего излучения в инфракрасном диапазоне, методом абсорбционной спектроскопии можно анализировать оптические свойства как поверхности, так и объема пленки. При $\theta=13$ и $40^{\circ}$ анализировались колебания связей во внутренних слоях пленки, а при $\theta=70^{\circ}-$ на ее поверхности. Как видно из рис. 3, интенсивность полосы поглощения в области $800 \mathrm{~cm}^{-1}$ увеличивается при скользящем угле падения (рис. 3, кривая 3). Следовательно, эта фаза формируется на поверхности пленочной структуры $\mathrm{Co}-\mathrm{TiO}_{2} / \mathrm{Pt} / \mathrm{Si}$. Кроме того, наблюдается смещение полосы $v(\mathrm{Ti}-\mathrm{O})$ в область более высоких волновых чисел (от 824 до $832 \mathrm{~cm}^{-1}$ ), что связано с образованием более сильных связей на поверхности по сравнению с объемом пленки.

Таким образом, методом ИК спектроскопии обнаружена полоса поглощения в области $825-834 \mathrm{~cm}^{-1}$, указывающая на замещение титана кобальтом и присутствие кислородных вакансий в решетке $\mathrm{TiO}_{2}$, модифицированной кобальтом.

Изучали влияние длительности ИФО и, следовательно, ее энергетическое воздействие, на структуру поверхности пленочной системы $\mathrm{Co}-\mathrm{TiO}_{2} / \mathrm{Pt} / \mathrm{Si}$. Нa рис. 4 представлены ИК спектры RAS при скользящем угле падения $70^{\circ}$, полученные после ИФО при силе тока $216 \mathrm{~A} \mathrm{в} \mathrm{течение} 1,1.2,1.3 \mathrm{~s}$ с энергией воздействия $E=90,100,120 \mathrm{~J} / \mathrm{cm}^{2}$ соответственно. По мере увеличения длительности импульса растет отношение интенсивности колебательных мод LO и TO. Это обусловлено увеличением степени дисперсности отражающих частиц в синтезируемой пленке. По мере уменьшения размера частиц уменьшается эффективная поверхность 


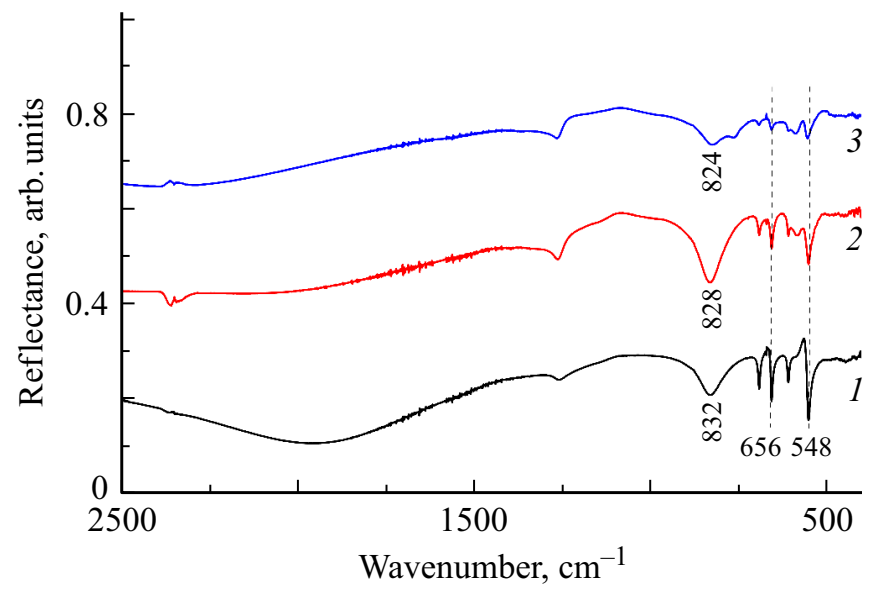

Рис. 4. Инфракрасные спектры, полученные при угле падения $70^{\circ}$ пленочной системы $\mathrm{Co}-\mathrm{TiO}_{2} / \mathrm{Pt} / \mathrm{Si}$ после ИФО в течение 1 (1), 1.2 (2), $1.3 \mathrm{~s}(3)$.

отражающей частицы с нормальным отражением за счет увеличения кривизны поверхности. Это наряду с увеличением рассеяния под большим углом и приводит к усилению отношения интенсивностей колебательных мод LO и TO. Таким образом, увеличение длительности ИФО приводит к росту дисперсности исследуемой пленки.

На рис. 5 представлен зависимость спектра отражения пленки от энергии фотонов при угле падения $8^{\circ}$ в видимой и ультрафиолетовой областях спектра $(190-900 \mathrm{~nm})$. Сложная структура спектра отражения, по нашему мнению, определяется наличием в пленке нескольких фаз с различной шириной запрещенной зоны, а отражение происходит не только от поверхности, но и от границы раздела пленка-подложка. В этом случае наблюдаем суммарный спектр зеркального отражения и пропускания через двойной слой пленки.

Для анализа спектра использовали методику расчета величины $2 \alpha d$ [29], по формуле

$$
2 \alpha d=\ln \left[\left(R_{\max }-R_{\min }\right) /\left(R-R_{\max }\right)\right],
$$

где $\alpha-$ коэффициент поглощения, $d-$ толщина пленки, $R$ - коэффициент отражения. Ширину запрещенной зоны и тип оптического перехода определяли по соотношению Тауца [30]

$$
\alpha h v=A\left(h v-E_{g}\right)^{n},
$$

где $h v-$ энергия фотона, $A-$ константа, имеющая отношение к материалу, а $n-$ величина, зависящая от природы перехода (2 для прямого разрешенного перехода, $2 / 3$ для прямого запрешенного перехода и $1 / 2$ для непрямого разрешенного перехода). Спектр поглощения гетерогенной структуры является суперпозицией спектров поглощения отдельных фаз, поэтому на спектре наблюдается сложный край, состоящий из трех участков (рис. 6).
Экспериментальный спектр поглощения хорошо приближается функцией (1) со значением $n=2$ в (2), что предполагает наличие в пленке полупроводниковых фаз с прямыми переходами при этих энергиях. Линейные участки были экстраполированы к нулевому значению $(\alpha h v)^{2}$ с целью определения начала края собственного поглощения при прямых межзонных переходах.

Исследование оптического поглощения гетероструктуры $\mathrm{Co}-\mathrm{TiO}_{2} / \mathrm{Pt} / \mathrm{Si}$ указывает на преимущественное существование в пленках фаз с энергиями оптических переходов $1.45,1.84$ и $2.65 \mathrm{eV}$. В ряде работ было показано, что для $\mathrm{Co}_{3} \mathrm{O}_{4}$ характерны многозонные переходы и возможность вырождения валентной зоны, а значения энергий зависят от способа получения оксида $\mathrm{Co}_{3} \mathrm{O}_{4}$, размера и формы частиц. Для кристаллических пленок $E_{g}$ составило значение $1.88,2.13 \mathrm{eV}[31]$ и $1.48-1.51 \mathrm{eV}$ для низкоэнергетической области и $2.08-2.11 \mathrm{eV}$ для высокоэнергетической области при отжиге пленок при $T=300$ и $500^{\circ} \mathrm{C}$ соответственно [32]. Для наночастиц и объемных образцов получали большие значения 1.77 и $3.15 \mathrm{eV}$ [33], 1.62 и $3.11 \mathrm{eV}$ для нелегированных наночастиц $\mathrm{Co}_{3} \mathrm{O}_{4}$ размером $25 \mathrm{~nm}$ в [34]. Увеличение размера кристаллитов при увеличении температуры отжига или легировании, например, Li приводило к увеличению энергии оптических переходов до 3.29-3.98 eV. Энергия перехода $E_{g}=1.84 \mathrm{eV}$ для полученных нами композитных пленок может быть отнесена к процессу переноса заряда $\mathrm{O}^{2-}-\mathrm{Co}^{2+}$ (энергия оптического перехода электрона из валентной зоны в зону проводимости). Наличие в оксиде кобальта $\mathrm{Co}_{3} \mathrm{O}_{4}$ центров $\mathrm{Co}^{3+}$ приводит к появлению уровня внутри запрещенной зоны (уровень $\mathrm{Co}^{3+}$ расположен ниже зоны проводимости), a $E_{g}=1.45 \mathrm{eV}$ может быть связана с переносом заряда заряда $\mathrm{O}^{2-}-\mathrm{Co}^{3+}$. Эти значения находятся в хорошем соответствии со значениями прямых разрешенных оптических переходов для наночастиц $\mathrm{Co}_{3} \mathrm{O}_{4}$, полученными в ряде работ $[31,33,35,36]$. Энергия перехода

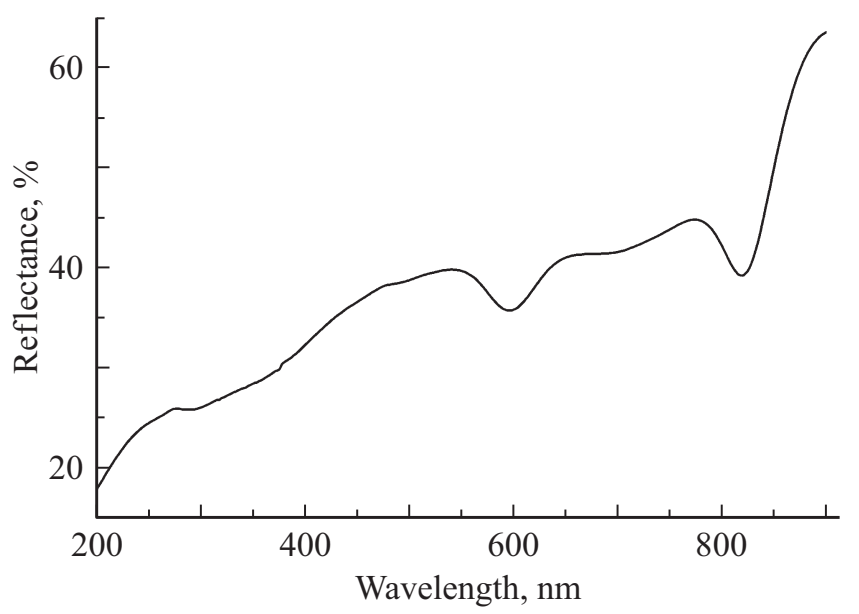

Рис. 5. Зависимость спектра отражения пленки образца системы $\mathrm{Co}-\mathrm{TiO}_{2} / \mathrm{Pt} / \mathrm{Si}$ после ИФО от энергии фотонов при угле падения $8^{\circ}$. 

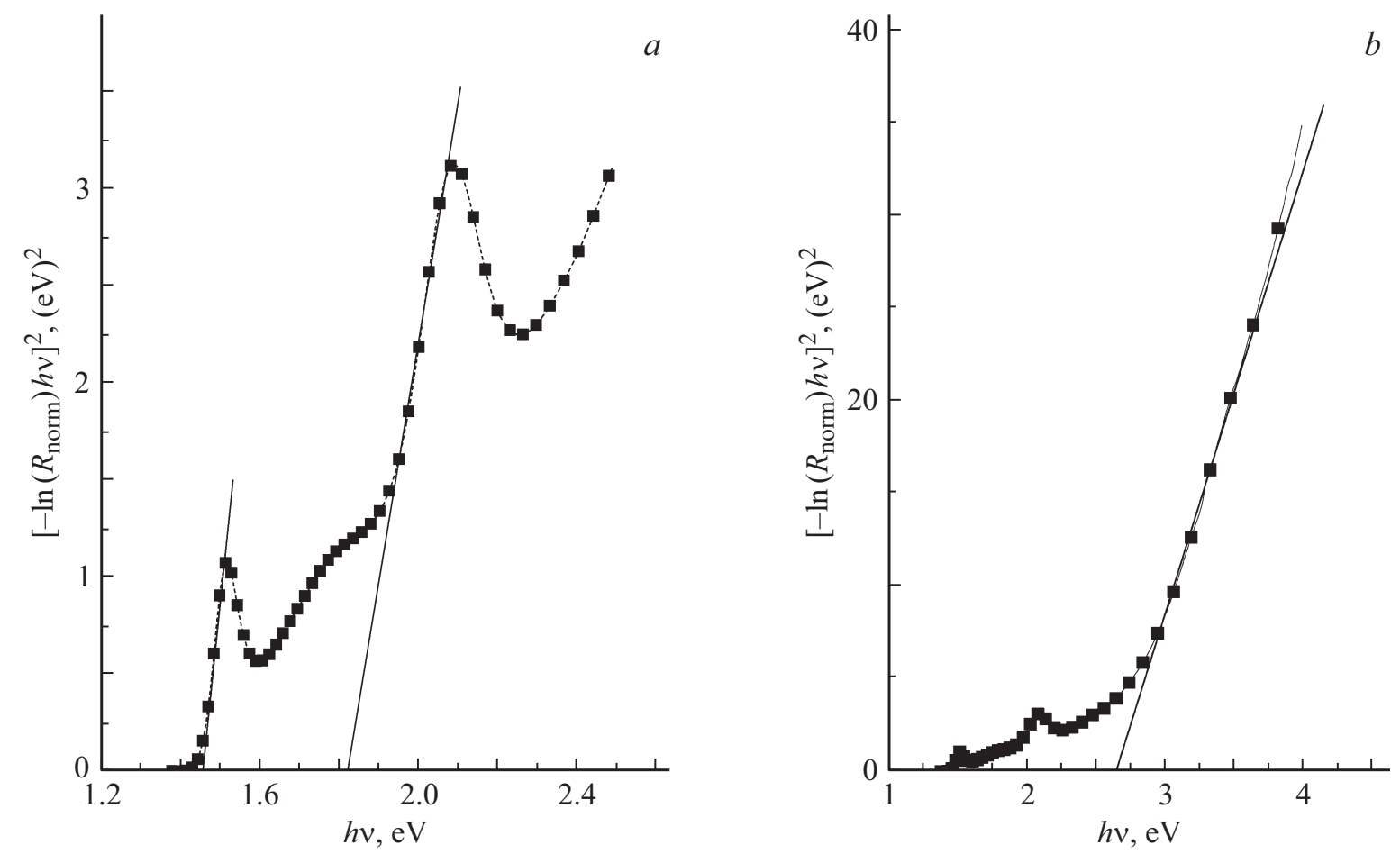

Рис. 6. Зависимость $(\alpha h v)^{2}$ от энергии фотонов для пленочной системы Co- $\mathrm{TiO}_{2} / \mathrm{Pt} / \mathrm{Si}$ после ИФО.

$E_{g}=2.65 \mathrm{eV}$ совпадает со значениями энергий прямых переходов для многослойных пленок $\mathrm{CoO}$ (толщиной от 135 до $522 \mathrm{~nm}$ ), которые изменялись в диапазоне $2.0-2.78 \mathrm{eV}$ [37]. Для каждой из фаз исследуемой в настоящей работе пленки оскида титана, модифицированной кобальтом, наблюдается уменьшение ширины запрещенной зоны по сравнению с объемными и пленочными образцами, полученными другими авторами. Наблюдаемый эффект можно отнести к наличию дефектов (в основном вакансий) в межзеренных областях, которые образуются в результате взаимодействия $\mathrm{CoO}$ и $\mathrm{TiO}_{2}$.

\section{Заключение}

Магнетронным распылением кобальта на поверхность поликристаллических пленок рутила с последующей ИФО на воздухе были синтезированы пленки, состоящие из оксидов кобальта: $\mathrm{Co}_{3} \mathrm{O}_{4}, \mathrm{CoO}$, и титана $\mathrm{TiO}_{2}$ в структуре рутила. В процессе модификации происходит формирование нанокристаллической (с размерами зерен $\sim 50 \mathrm{~nm}$ ) пленки, поверхность которой проявляет магнитные свойства.

Методом ИК спектроскопии установлено, что помимо ТО (653 и $548 \mathrm{~cm}^{-1}$ ) и соответствующих им LO $\left(689\right.$ и $\left.606 \mathrm{~cm}^{-1}\right)$ колебательных мод связи $\mathrm{Co}-\mathrm{O}$, характерных для $\mathrm{Co}_{3} \mathrm{O}_{4}$ в структуре шпинели, появляется дополнительная полоса в области $800 \mathrm{~cm}^{-1}$, обусловленная колебаниями связи $v(\mathrm{Ti}-\mathrm{O})$. Смещение этой полосы в область низких длин волн по сравнению с колебания связи в нелегированных пленках $\mathrm{TiO}_{2}$ вызвано замещением ионами кобальта $\mathrm{Co}^{2+}$ ионов $\mathrm{Ti}^{+4}$ в узлах кристаллической решетки рутила, которое сопровождается генерацией вакансий. Взаимодействие двух оксидов происходит на межзеренной границе на поверхности пленки, о чем свидетельствует увеличение интенсивности этой полосы при скользящем угле падения. Оптические измерения поглощения показали, что увеличение энергии ИФО приводит к росту дисперсности пленки. Магнитный сигнал от поверхности может быть следствием взаимодействия антиферромагнитного оксида $\mathrm{Co}_{3} \mathrm{O}_{4}$ и парамагнитного $\mathrm{TiO}_{2}$, которое активируется ИФО и приводит к образованию сложных оксидов.

Исследование оптического поглощения указывает на преимущественное существование в пленках фаз с прямозонными оптическими переходами с энергией 1.43 и 1. $83 \mathrm{eV}$ для $\mathrm{Co}_{3} \mathrm{O}_{4}$ и $2.65 \mathrm{eV}$ для кубической фазы $\mathrm{CoO}$.

Таким образом, модификация кобальтом оксида титана посредством магнетронного распыления и ИФО привела к формированию пленки, в которой край поглощения значительно сдвигается в видимую область спектра.

\section{Благодарности}

Результаты исследований получены на оборудовании Центра коллективного пользования Воронежского государственного университета. 


\section{Список литературы}

[1] Ngo T.Q., Posadas A., Seo H., Hoang S., McDaniel M.D., Utess D., Triyoso D.H., Mullins C.B., Demkov A.A., Ekerdt J.G. // J. Appl. Phys. 2013. V. 114. P. 084901. doi 10.1063/1.4819106

[2] Pawar S.G., Patil S.L., Chougule M.A., Patil V.B. // J. Mater. Sci.: Mater. in Electron. 2011. V. 22. N 3. P. 260. doi 10.1007/S10854-010-0125-8

[3] Kumar S.G., Devi L.G. // J. Phys. Chem. A. 2011. V. 115. N 46. P. 13211. doi 10.1021/jp204364a

[4] Pfeil T.L., Pourpoint T.L., Groven L.J. // Int. J. Hydrogen Energy. 2014. V. 39. P. 2149.

doi 10.1016/j.ijhydene.2013.11.104

[5] Liu M., Li Y., Wang K., Luo Y., Hou S., Wang P., Pang F., Ji Fe., Zhao L. // Ceramics International. 2018. V. 44. N 16. P. 19631. doi 10.1016/j.ceramint.2018.07.213

[6] Peng S. J., Li L.L., Hu Y.X., Srinivasan M., Cheng F., Chen J., Ramakrishna S. // ACS Nano. 2015. V. 9. N 2. P. 1945. doi $10.1021 / \mathrm{nn} 506851 \mathrm{x}$

[7] Jang G.-S., Ameen S., Akhtar M.S., Shin H.-S. // Ceramics International. 2018. V. 44. N 1. P. 588. doi 10.1016/j.ceramint.2017.09.217

[8] Makhlouf S.A. // J. Magn. Magn. Mater. 2002. V. 246. N 1-2. P. 184. doi 10.1016/s0304-8853(02)00050-1

[9] Yamaura H., Moriya K., Miura N., Yamazoe N. // Sens. Actuators B. 2000. V. 65. P. 39. doi 10.1016/s09254005(99)00456-6

[10] Rao C.N.R., Raveau B. Transition Metal Oxides. N.Y.: VCH, 1995. 338 p. doi 10.1002/amo.860050510

[11] Berger A., Pechan M.J., Compton R., Jiang J.S., Pearson J.E., Bader S.D. // Phys. Rev. B. 2001. V. 306. N 1-4. P. 235. doi 10.1016/s0921-4526(01)01010-9

[12] Liao L., Zhang Q., Su Z. et al. // Nature Nanotechnol. 2013. V. 9. N 1. P. 69. doi 10.1038/nnano.2013.272

[13] Mousavand T., Naka T., Sato K., Ohara S., Umetsu M., Takami S., Nakane T., Matsushita A., Adschiri T. // Phys. Rev. B. 2009. V. 79. N 14. P. 144411. doi 10.1103/physrevb.79.144411

[14] Chen J., Wu X., Selloni A. // Phys. Rev. B. 2011. V. 83. N 24. P. 245204. doi 10.1103/physrevb.83.245204

[15] Chen Y.H., Zhou J.F., Mullarkey D., O'Connell R., Schmitt W., Venkatesan M., Coey M., Zhang H.Z. // AIP Advances. 2015. V. 5. N 8. P. 10.1063/1.4928494. doi 10.1063/1.4928494

[16] Choudhury B., Choudhury A., Maidul Islam A.K.M., Alagarsamy P., Mukherjee M. // J. Magn. Magn. Mater. 2011. V. 323. N 5. P. 440. doi 10.1016/j.jmmm.2010.09.043

[17] Pellicer E., Cabo M., Rossinyol E. // Adv. Funct. Mater. 2012. V. 23. N 7. P. 900 . doi $10.1002 / \mathrm{adfm} .201201486$

[18] Иевлев В.М. // Успехи химии. 2013. Т. 82. № 9. С. 815; Ievlev V.M. // Russ. Chem. Rev. 2013. V. 82. N 9. P. 815. doi 10.1070/RC2013v082n09ABEH004357

[19] Hashim A.H., Zayed A.O.H., Zain S.M., Lee V.S., Said S.M. // Appl. Surf. Sci. 2018. V. 427. P. 1090. doi 10.1016/j.apsusc.2017.09.085

[20] Serrano A., Fernandez Pinel E., Quesada A. // Phys. Rev. B. 2009. V. 79. N 14. P. 144405. doi 10.1103/PhysRevB.79.144405 G.

[21] Lenglet M., Lopitaux J., Terrier L., Chartier P., Koenig J.F., Nkeng E., Poillerat G. // J. de Phys. IV. 1993. V. 03. N C9. P. C9-477. doi 10.1051/jp4:1993951
[22] Merino M.C.G., Nasisi L.D.T., Montoya W.M. // Proc. Mater. Sci. 2015. V. 8. P. 534. doi 10.1016/j.mspro.2015.04.105

[23] Pan G.X., Xia X.H., Cao F., Chen J., Zhang Y.J. // Electrochim. Acta. 2015. V. 173. P. 385. doi 10.1016/j.electacta.2015.05.078

[24] Cheng K., Cao D. X., Yang F., Xu Y., Sun G., Ye K., Wang G. // J. Power Sources. 2014. V. 253. P. 214. doi 10.1016/j.jpowsour.2013.12.068

[25] Makhlouf M.Th., Abu-Zied B.M., Mansoure T.H. // Phys. Chem. 2012. V. 2. N 6. P. 86. doi 10.5923/j.pc.20120206.01

[26] Li Y., Qiu W., Qin F., Fang H., Hadjiev V.G., Litvinov D., Bao J. // J. Phys. Chem. C. 2016. V. 120. N 8. P. 4511. doi 10.1021/acs.jpcc.5b11185

[27] Vasconcelos D.C.L., Costa V.C., Nunes E.H., Sabioni A.C.S., Gasparon M., Vasconcelos W.L. // Mater. Sci. Appl. 2011. V. 2. N 10. P. 1375. doi 10.4236/msa.2011.210186

[28] Khanahmadzadeh S., Enhessari M., Solati Z., Mohebalizadeh A., Alipouramjad A. // Mater. Sci. Semicond. Process. 2015. V. 31. P. 599. doi 10.1016/j.mssp.2014.12.043

[29] Kumar V., Sharma S.Kr., Sharma T.P., Singh V. // Opt. Mater. 1999. V. 12. P. 115. doi 10.1016/s0925-3467(98)00052-4

[30] Tauc J. // Amorphous and liquid semiconductors / Ed by Tauc J. N.Y.: Premium Press, 1974. P. 159. doi. 10.1007/9781-4615-8705-7

[31] Barreca D., Massignan C., Daolio S., Fabrizio M., Piccirillo C., Armelao L., Tondello E. // Chem. Mater. 2001. V. 13. P. 588. doi $10.1021 / \mathrm{cm} 001041 \mathrm{x}$

[32] Louardi A., Rmili A., Ouachtari F., Bouaoud A., Elidrissi B., Erguig H. // J. Alloys and Comp. 2011. V. 509. N 37. P. 9183. doi 10.1016/j.jallcom.2011.06.106

[33] Xu R., Zeng H.C. // Langmuir. 2004. V. 20. N 22. P. 9780. doi 10.1021/la049164+

[34] Gu F., Li C., Hu Y., Zhang L. // J. Cryst. Growth. 2007. V. 304. N 2. P. 369. doi 10.1016/j.jcrysgro.2007.03.040

[35] Vijayakumar S., Ponnalagi A.K., Nagamuthu S., Muralidharan G. // Electrochim. Acta. 2013. V. 106. P. 500. doi 10.1016/j.electacta.2013.05.121

[36] He T., Chen D., Jiao X., Wang Y., Duan Y. // Chem. Mater. 2005. V. 17. N 15. P. 4023. doi $10.1021 / \mathrm{cm} 050727 \mathrm{~s}$

[37] Purushothaman K.K., Sethuraman B., Anupama M.P., Dhanasankar M., Muralidharan G. // Mater. Sci. Semicond. Process. 2013. V. 16. N 6. P. 1410. doi 10.1016/j.mssp.2013.04.023 